\title{
Language contact between Uyghur and Chinese in Xinjiang, PRC: Uyghur elements in Xinjiang Putonghua
}

ABLIMIT BAKI

Abstract

This article reports on language contact between Uyghur and Chinese in the Uyghur Autonomous Region of Xinjiang in China. It proposes that the massive influx of Han Chinese migrants to Xinjiang resulted in intense language contact between the speakers of Uyghur and Chinese. As a result of this, these two languages are mutually affecting each other in the region. The focus of this article is on the influence of Uyghur on Putonghua in Xinjiang. Four categories of this influence are reported: (1) phonological influence that produces Putonghua sounds similar to Uyghur sounds, exemplified by the dropping of tones, the changing of sounds and the addition of certain sounds which are closer to those in Uyghur; (2) lexical influence, exemplified by introducing into Putonghua elements of the Uyghur lexicon which are then adapted to resemble Putonghua lexical forms; (3) grammatical influence that produces Putonghua grammatical structures similar to those of Uyghur, exemplified by changing word order in Putonghua grammatical structures; and (4) semantic influence that makes use of Uyghur expressions in Putonghua through literal translation, exemplified by using Uyghur similes and metaphors directly to describe people and things in certain contexts.

Keywords: Uyghur, Putonghua; contact situation; language-to-language influence; language transfer; agentivity; borrowing; imposition; variety; interlanguage.

\section{Introduction}

There is an important literature on the mutual influence of languages in contact situations. Many scholars have shown that the direction of the influence is not only from a majority language to a minority language, but also vice versa. Although much has been done on language-to-language influence in many 
contact situations, such as research on the influence of Cantonese on Putonghua (Snow 2004), influence of Irish on the English spoken in Ireland (Moody et al. 1991), the influence of Turkish and Arabic on the Dutch spoken by Moroccans and Turkish in Holland (Vermeer 1985), and the influence of Quechua on the Spanish spoken in Peru (Manley 2007), much less has been said about the influence of Uyghur on Chinese in western China. The aim of this article is to examine the influence of Uyghur, a regional language in Xinjiang, on Standard Putonghua (STDPTH), or Mandarin Chinese, the national language of the $\mathrm{PRC}$, as a result of intense language contact in the region.

The data used in this article are taken from a corpus based on my fieldwork in Xinjiang. The corpus was collected in Xinjiang during the summer months of 2006, 2009 and 2010 by using the method of participant observation, a powerful research tool used for collecting data investigating language contact. The aim of the corpus collection was to find what elements of Uyghur would be used in the spontaneous conversation between Uyghurs and Han in public domains such as neighborhoods, shopping centers, markets, post offices, banks, hospitals, buses and restaurants. Participants for this study are Uyghurs and Han. The participants were randomly observed in different settings. The participants included various kinds of men and women of all ages. This article is significant in that it is the first attempt to investigate the influence of the minority language on the majority language in a lesser known contact situation in China.

\section{Language contact and change}

In a language contact situation, it is generally hard to find cases where no languages are influenced. This is because language contact often brings about changes to the languages used in the community. Language-to-language influence is not only confined to language contact situations. To some extent, it is also characteristic of second language acquisition. Some of the concepts often used in the literature on second language acquisition to describe language-tolanguage influence are language transfer, competence in second language, and interlanguage.

\subsection{Language transfer}

Languages in contact influence each other in several ways (Thomason 2001). One area of influence is language transfer, the introduction of features of one language into another language (Odlin 1989: 1). In a language contact situation where societal bilingualism is the norm, speakers from one language often transfer features of their own language to the other language. The transference of linguistic material from one language (the source language, SL) into another 
language (the recipient language, $\mathrm{RL}$ ) may give rise to systematic patterns of language variation, which is known as language change (Thomason 2001). Van Coetsem (1988: 87) distinguishes two main types of transfer in language contact: borrowing and imposition. From the perspective of the recipient language, borrowing is defined as "the incorporation of foreign features into a group's native language by speakers of that language: the native language is maintained but changed by the addition of the incorporated features" (Thomason and Kaufman 1988: 37). Imposition, on the other hand, is usually defined from the perspective of the source language, that is, as "copying from a sociolinguistically dominant code into a sociolinguistically dominated code" (Johanson 2002: 290).

Van Coetsem (2000: 35) explains these two main transfer types using the notion of language agentivity: RL agentivity (borrowing) and SL agentivity (imposition). According to van Coetsem, in RL agentivity (borrowing), features from a source language are transferred into a recipient language by the speakers of the RL who are more proficient in that language. In SL agentivity (imposition), however, features are again transferred from a source language into a recipient language, but this time it is by the agency of speakers of the SL who are proficient in the SL (their dominant language) but are less fluent in the RL (the dominated language). Van Coetsem (2000: 76) also maintains that a certain feature of the SL does not have to be imposed on the RL as a whole. Instead, individual elements or aspects of it may be transferred.

Studies on language transfer often examine which features of a language can be transferred to the other language. Thomason and Kaufman (1988: 14) claim that "as far as the strictly linguistic possibilities go, any linguistic feature can be transferred from any language, to any other language". According to this claim, any features of a language can be transferred from one language to the other language.

Language transfer is sometimes considered as language interference. Dulay et al. (1982) defined interference as the automatic transfer of the surface structure of the first language onto the surface structure the second language. Byram (2004: 633) maintains that there are positive transfers and negative transfers. When transferred phonological, morphological, syntactic and semantic features from one language are acceptable to use in a second language, there is positive transfer, but when errors occur due to the imperfect learning of second languages, there is negative transfer.

\subsection{Competence in the second language}

Conditions under which a second language is acquired by the individuals and the community are related to the proficiency level in the second language. 
Favorable conditions may produce fluent speakers of the second language while unfavorable conditions may produce imperfect learning of the second language. Odlin (1989: 155) maintains that among the most important factors is the social context. Coelho (1998: 81) argues that second language learners may be able to perform very well in an appropriate learning environment. According to Coelho, learners learn new content, skills and knowledge of second language at the same time under a favorable learning environment. Bilingualism and attitudes of speech communities have been important in second language proficiency. The degree of bilingualism has an effect on one's competence in the second language. Swain and Lapkin (1991: 203) claim that additive bilingualism is often associated with positive effect while subtractive bilingualism with negative effect. Attitudes of speech communities also have effects on second language proficiency. Brisk (2006: 83) found that positive attitudes are correlated with competence in the target language. According to Brisk, improving attitudes is an important aspect of second language development. Silva-Corvalán (1995: 10) also recognizes the impact of extra-linguistic factors on the competence of the second language. Some of the factors she identifies are the attitudes that speakers have toward each of their two languages and the attitudes of the speech communities.

\subsection{Interlanguage}

An interlanguage is the type of language used by second and foreign language learners who are in the process of learning a language (Selinker 1972). The notion of interlanguage implies that interlanguage has its own phonological, morphological, syntactic, lexical and semantic system. Davies (1989) describes a number of characteristics of interlanguage: "the language of the learner" (Davies 1989: 460); "a point on the way to a full natural language" (1989: 461); and “a development process involving the learner's systematic approximations toward the target language" (1989: 448). Most generally, interlanguage is a changing language system which cannot be considered a complete language.

It is necessary to differentiate an interlanguage from a variety of the standard language. Davies (1989) distinguishes between English as an international language and an interlanguage. According to Davies, the notion of interlanguage can not be used to describe a new societal variety of English, because an individual has an interlanguage, whereas a community has a variety. In discussing the individual and the community acquisition of second language, Zhou (2006) made a distinction between interlanguages and varieties. According to Zhou, an interlanguage is an individual phenomena, accounting for individual variation, whereas a new variety of a language is societal, based on a 
communal norm. Zhou further maintains that biological factors determine the outcome of individual second language acquisition, but the outcome of community second language acquisition may produce new varieties of the second language, or the standard language, as the result of language contact.

\section{The language contact situation in Xinjiang}

\subsection{The contact situation between Uyghur and Chinese}

There are several language contact situations in Xinjiang depending on the languages involved. According to the Chinese Census (2003), Xinjiang has a population of 19.25 million, comprised of 11 major ethnic groups. Uyghurs and Han Chinese are the two principal ethnic groups. Other ethnic groups residing throughout Xinjiang include Kazakhs, Hui, Kyrgyz, Mongols, Tajiks, Xibe, Uzbeks, Russians and Tatars. The languages of these ethnic groups are usually classified into three major language families: Altaic (Uyghur, Kazakh, Kyrgyz, Mongolian, Uzbek, Tatar and Xibe), Sino-Tibetan (Chinese) and Indo-European (Russian and Tajik). At the regional level, there is the contact between the two principal languages (Uyghur and Chinese). At the local level, however, there is the contact between small languages (languages with a small number of speakers) and one of the two principal languages, as well as contact between two small languages, or multiple languages in contact. There is also contact between different Chinese dialects throughout the region. Different types of language contact situations may produce different linguistic effects. The focus of this article is on the contact situation between Uyghur and Chinese.

Although Uyghurs are a minority at the national level, they comprise the numeric majority at the regional level in Xinjiang. According to the Chinese Census (2003), the total Uyghur population of Xinjiang is about 8.3 million people (about $45 \%$ of the total Xinjiang population). Uyghur is the language spoken mainly by Uyghurs as their native language. It is also the language used at all levels of Tajik education in Xinjiang. In comparison, the total population of the Han in Xinjiang is about 7.5 million people (about $41 \%$ of Xinjiang's total population). The language of the Han is Chinese, which comprises a number of "so-called" dialects. For the overwhelming majority of the Uyghurs, Chinese is a second language. It is acquired by the Uyghur individuals at school and in the community.

In discussing a language contact situation, it is often important to identify causes that make language contact take place. Li (2010: 127) maintains that a number of factors cause language contact to take place. These include politics, natural disaster, religion, culture, economy and technology. Uyghurs and 
Chinese have been in constant contact for centuries. Historically, language contact between speakers of Uyghur and Chinese resulted from trade, wars, conquest and colonialism. In recent years, language contact between Uyghur and Chinese in Xinjiang has taken place mainly because of Han migration. According to the official Chinese record, the proportion of Han in Xinjiang has increased from 6\% in 1949 to a close second in 2000 (Chinese Census 2003). The significant increase in the number of the Chinese speakers in Xinjiang has intensified the degree of language contact in the region.

\subsection{Xinjiang Putonghua}

Han Chinese migrants into Xinjiang have brought with them their own language, Chinese. Chinese is an umbrella term covering all Chinese dialects. It is generally agreed that Chinese dialects may be divided into eight major groups, namely: Mandarin, Jin, Wu, Gan, Xiang, Min, Yue (Cantonese) and Hakka (Chen 1999: 205). Mandarin, or Putonghua (the common language), has the largest number of speakers, scattered in wide geographical regions throughout the country. Chen (1999: 205) maintains that each of these dialects comprises a group of genetically related varieties. According to Chen, there are eight subgroups in Putonghua, three of which are relevant to this study. These are Beijing, Lan-Yin (representing Lanzhou and Yinchuan in Gansu and Ningxia provinces) and Zhongyuan (representing the central regions).

Chinese spoken in Xinjiang is commonly known as Xinjiang Putonghua (XJPTH), which is a variety of Standard Putonghua (STDPTH). Several subvarieties of XJPTH have been proposed according to the distribution of the speakers of the Chinese language in the region. Zhou (2007) distinguished three sub-varieties: (1) Lan-Yin Northern Xinjiang Mandarin Variety, (2) Zhongyuan Southern Xinjiang Mandarin Variety, and (3) Beijing Mandarin Variety. Speakers of Variety 1 can be found mainly in Northern and Eastern Xinjiang, Variety 2 mainly in Southern and Western Xinjiang and Variety 3 in newly established industrial cities in Northern Xinjiang. These three varieties of XJPTH are differentiated by variations of sounds (vowels, consonants and tones), lexis and certain grammatical structures, and they are primarily used by speakers of the Chinese language (Zhou 2007; Li 2005; Ma 2007).

\subsection{Xinjiang Spoken Putonghua}

There is still another sub-variety of Xinjiang Putonghua - the Xinjiang Spoken Putonghua (XJSPTH). XJSPTH is characterized by having many Uyghur elements as a result of the influence of Uyghur on the Chinese lan- 
guage. XJSPTH is currently used as the lingua franca between many speakers of Uyghur who are less proficient in Putonghua, and it is accepted and used by many monolingual Putonghua speakers when communicating with each other in informal situations. Until now, XJSPTH remains in spoken form only in Xinjiang and it has not been recognized as a variety of Xinjiang Putonghua. But, from the functional perspective, it is justifiable to treat XJSPTH as a variety of Putonghua spoken in Xinjiang. The purpose of this article is to attract attention to XJSPTH. From the Uyghur perspective, XJSPTH is the outcome of language contact between Uyghur and Chinese. From the Chinese perspective, XJSPTH represents a different variety of XJPTH.

\subsection{Putonghua competence of Uyghurs}

The emergence of XJSPTH is largely due to the conditions under which $\mathrm{Pu}$ tonghua is acquired by Uyghur individuals and the Uyghur community. The first condition is related to the Putonghua instruction in Uyghur schools in Xinjiang. China's legislation allows Xinjiang to decide its own education programme, including the types of school and the medium of instruction (Dwyer 2005). There are two types of ethnically separated schools: schools for the minorities and schools for the Han. All minorities which have written scripts are allowed to have separate schools, with their native languages used as the medium of instruction. Accordingly, there are Uyghur schools, Kazakh schools, Han Chinese schools and so on. The medium of instruction in Uyghur schools is Uyghur and students learn Putonghua as a second language from grade 3 until they graduate from school at the age of 18 or 19. In Han Chinese schools, Chinese is the medium of instruction and students learn English as a foreign language, following the same pattern as Uyghurs learning Putonghua. Ethnically separated schools in Xinjiang have been unable to achieve the goal of Putonghua instruction, that is, to be able to produce students who are Min-Han jiantong, proficient in both Uyghur and Putonghua, or balanced bilinguals. Many Uyghur students are, in fact, imperfect learners of Putonghua (Kang 2003). This type of education in Xinjiang has been responsible for the longterm existence of societal bilingualism, a society in which each group is monolingual with a few bilingual individuals (Appel and Muysken 2006: 2). According to this concept, societal bilingualism in Xinjiang is characterized by the co-existence of monolingual Uyghurs and monolingual Han in Xinjiang but with a few bilingual Uyghurs with low competence in Putonghua.

The second condition is the Putonghua learning environment for the Uyghur community outside the classroom. The distribution of the Uyghurs and the Han in Xinjiang is quite uneven. The majority of the Han live in the north, while the majority of the Uyghurs are heavily concentrated in the south. This has 
created a disparity of the competence in Putonghua among the Uyghurs. More Uyghurs in the north are likely to be bilinguals compared to fewer Uyghurs in the south who are bilingual. In urban Xinjiang, only $20 \%$ of the population is Uyghur, while in rural Xinjiang, more than $80 \%$ of the population is Uyghur (Ma 2003: 128). As a result of this distribution, the Uyghur community in urban Xinjiang may attain a certain level of proficiency in Putonghua while the vast Uyghur community in rural Xinjiang manages no more than a few simple phrases of Chinese (Hess 2009: 412).

Extra-linguistic factors, such as the beliefs of the Uyghurs and the Han about Xinjiang, and the attitudes held by these two ethnic groups towards each other, may affect the competence of Putonghua among some Uyghurs. Uyghurs consider Xinjiang as their ancestral homeland (Starr 2004: 6). Many of the Han believe that Xinjiang is a minority region and their real native homeland is inland China. The attitudes of the Uyghurs and the Han Chinese are not positive towards each other. Most of the Uyghurs are resentful of the mass influx of Han migrants into the region (Moneyhon 2004) and both groups share mutual prejudice against each other (Kaltman 2007).

These unfavorable conditions may have kept the Uyghurs from achieving a higher proficiency level in Putonghua. Nevertheless, language contact between Uyghur and Chinese in Xinjiang requires the speakers of Uyghur to be the active agents in this language contact situation because Uyghurs can be bilinguals while the Putonghua speakers are monolingual. Uyghurs have intentionally or unintentionally imposed many features from their dominant language, Uyghur (SL) onto Putonghua (RL). Over the past 60 years, Putonghua in Xinjiang has undergone phonological, lexical, grammatical and semantic changes under the strong influence of Uyghur (Niu 2000), and has gradually developed into XJSPTH, a new variety of XJPTH. Changes to STDPTH as a result of language contact account for the emergence of XJSPTH in Xinjiang.

\section{Uyghur elements in Standard Putonghua in Xinjiang}

The data will be presented according to the aims of this article. These data include phonological, lexical, grammatical and semantic influences of Uyghur on STDPTH.

\subsection{Phonological elements}

Uyghur speakers tend to replace STDPTH sounds with the phonemes of their own language. Phonetic replacement of this kind is sometimes made by violating the Chinese phonetic system, and is sometimes made by substituting 
STDPTH sounds closest to the Uyghur sounds. A number of contact phenomena in phonology are found at various levels. These include dropping tones, substitution of sounds, extending the length of the vowel and the changing of stressed syllables.

4.1.1. Dropping tones. The first phenomenon in the phonological influence of Uyghur on STDPTH is found at the suprasegmental level. STDPTH is a tonal language (Gao 2000), and according to Gao, STDPTH distinguishes four major tones: first tone (a high-level tone), second tone (a mid-rising tone), third tone (a low-dipping tone) and fourth tone (a high-falling tone). There is also a neutral tone, which is often excluded from the number of the tones. Tones are important in STDPTH, as they are used to signify meanings (Liu et al. 2007). Therefore, all words must carry tones. By comparison, Uyghur is a non-tonal language. Tones are completely dropped in XJSPTH when Uyghur speakers are communicating with Chinese speakers. This can be exemplified by:

\section{(1) a. XJSPTH: wangba \\ b. STDPTH: wăngbā 网吧 \\ 'internet café'}

The imposition of dropping the tones of STDPTH sounds is not unique to Uyghur learners of the Chinese language. Many speakers of non-tonal languages tend to ignore the tones when speaking Mandarin Chinese because of the lack of such a phonological pattern in their own languages. This process of dropping tones in XJSPTH, within the phonological paradigm of the Chinese language, exemplifies the intense language contact with Uyghur.

4.1.2. Substitution of sounds. The second phenomenon is the substitution of certain vowels and consonants in STDPTH with other sounds similar or closer to Uyghur vowels and consonants. It is quite common for L2 speakers to substitute the phonemes of their own languages for foreign sounds. One feature of STDPTH is that it has a number of diphthongs which do not exist in the Uyghur phonetic system. Uyghur speakers tend to substitute some of the STDPTH diphthongs with similar vowels in Uyghur. The vowels $i a$ and $u a$ in STDPTH are found to have been replaced by the single vowel $a$ and $u o$ by the single vowel $o$ in XJSPTH. Both Uyghurs and Chinese will know that $j a$ and hangga in XJSPTH actually refer to jiă (假) 'fake' and huăngguâ (黄瓜) 'cucumber' in STDPTH.

Another feature of STDPTH sounds is the presence of retroflex consonants such as $z h, c h$ and $s h$. There are no such sounds in the Uyghur phonetic system. In XJSPTH, these retroflex consonants have been replaced by alveopalatal consonants in Uyghur such as $j, q$ and $x$ because they are similar to the retroflex 
consonants in STDPTH. Another retroflex consonant in STDPTH is $r$. Norman (1988: 140) claims that, "The Chinese $r$ is pronounced with less friction than the comparable English fricative, and acoustically sounds much closer to the usual American pronunciation of $r$ " (Norman 1988: 140). In Uyghur, the sound $r$ is almost trilled. In XJSPTH, however, the retroflex $r$ is found to be pronounced as the Uyghur alveolar trilled $r$.

A third feature of STDPTH sound is the existence of the fricative consonant $f$. However, this sound is not originally in the Uyghur sound system. Due to the language contact with other languages, the fricative $f$ is changed into the plosive $p$ in Uyghur. Most Uyghurs and Han Chinese, for instance, are now aware that pangzi and papiao in XJSPTH are actually fángzi (房子) 'house' and fāpiào (发票) 'receipt' in SPTH.

4.1.3. Extension of the vowel length. The third phonological phenomenon is the extension of the vowel length. One distinctive feature of Uyghur is that the length of the vowel in the stressed syllable of certain adverbs and adjectives can be relatively extended for emphasis in some contexts. This is not the case in STDPTH. In XJSPTH, the length of the vowels is found to be extended in adverbs for the same purpose. For instance, the vowels in gāng (刚) 'just', yò (又) 'again' and hěn (很) 'very' are pronounced longer — as [ga: ng], [you:] and [he: $\mathrm{n}$ ] than they would be in STDPTH.

4.1.4. Change of the stressed syllable. The last phenomenon of the phonological influence of Uyghur on STDPTH is found again at the suprasegmental level. Ye and Xu (1997) claim that the native syllabic structural pattern of STDPTH is shown as $(\mathrm{C}) \mathrm{V}(\mathrm{C})$. The traditional native syllabic pattern of Uyghur, according to Mirsultan (1987), is represented as (C)(C)V(C)(C) or $(\mathrm{C})(\mathrm{C}) \mathrm{VV}(\mathrm{C})(\mathrm{C})$. Here "C" represents consonant, "V" represents vowels and "( )" represents a possible appearance. The stress pattern of STDPTH requires almost every syllable to be stressed, except for some syllables used as complements or suffixes. In Uyghur, the stress falls, in general, on the last syllable of most words. Quite often, 'pai 'chu 'suo (派出所) 'police station', 'gong' 'an 'ju (公安局) 'public security bureau' and 'Pu 'tong 'hua (普通话) 'Mandarin' in STDPTH are heard pronounced as pai qu 'so, gong an 'ju and Putong 'ha in XJSPTH.

\subsection{Lexical elements}

Lexical influence normally includes the introduction of lexical items from one language into another. Studies of foreign words often rely on the method of classification and categorization to examine which parts of speech and which 
concepts are introduced into a language. Words introduced from Uyghur into XJSPTH are mainly in the category of nouns concerning different kinds of typical Uyghur culture, such as tools, vegetables, food, plants, entertainment, clothes and festivals.

Examples for tools are piqiake (皮恰克) and kantuman (坎土曼) from the Uyghur words pichaq and katman, literally meaning 'knife' and 'mattock'. The lexeme piyazi (皮牙孜), meaning 'onion' is piyaz in Uyghur. Examples for food are nang (襄), ququ'er (曲曲尔) and wumaxi (吾马什) from the Uyghur words nan, chuchure and umach, literally meaning 'nan', 'wanton' and 'grits' respectively in English. An example of a plant is badanmu (巴旦木) from the Uyghur word, badam 'almond'. Words for entertainment are plentiful in XJSPTH. These words include dawazi (达瓦孜), mukamu (木卡姆), rewapu (热瓦普), duta'er (都塔尔) and maixilaipu (麦西来普) for the Uyghur words dawaz 'tight-rope walking', muqam, the traditional Uyghur music composed of twelve chapters, rawap, an instrument with five to seven strings, dutar, an instrument with two strings, and meshrep, originally meaning the harvest celebration held by farmers in the fields, but now meaning social gatherings with singing and dancing involved. One example of clothing is qapan (袷神) for the Uyghur word chapan, a collarless coat in the Uyghur tradition. Examples for festivals are words originating from the Islamic and Turkic tradition. Examples of these words include Gu'erbang (古尔邦) and Nuruzi (诺肉孜) for Kurban and Novruz festivals. These words are widely adopted not only in XJSPTH, but also in other sub-varieties of XJPTH because they are indigenous to Uyghur culture and there are no corresponding words available in STDPTH.

Research on lexical influence also examines how the introduced words are adapted phonologically. The examples above show that changes have been made to Uyghur words phonologically to make them sound as close to STDPTH as possible. It can be seen from the examples above that some of the original vowels and consonants in STDPTH are replaced by vowels and consonants that fit them into the phonological patterns of Uyghur. This is perhaps mainly due to the differences of the phonological patterns of these two languages. Uyghur has 32 phonemes, including 8 vowels and 22 consonants (Niyaz 1997). STDPTH, however, has 36 phonemes, including 14 vowels, and 22 consonants, in addition to the tones (Huang and Liao 1983). The data presented above exemplify how Uyghur words are adapted phonologically to fit into the phonological pattern of STDPTH.

\subsection{Grammatical elements}

A number of changes have been found in the grammatical structures of STDPTH. These include adding suffixes, changing word order from SVO to 
SOV, and changing word order in negation, and adverbials, in addition to the omission of the copulative verb and prepositions.

4.3.1. Adding suffixes. One aspect of the grammatical influence of Uyghur on STDPTH is found in the imposition of the Uyghur pattern of suffixes onto STDPTH words. A typical difference between Uyghur and STDPTH is that Uyghur is agglutinative while STDPTH is isolating. As a result of this, Uyghur has various morphological inflections and suffixes denoting number, case, tense etc., while STDPTH words normally consist of a single syllable without any inflectional suffixes. However, it has been observed that a couple of morphological changes have been introduced from Uyghur into STDPTH. These include the suffixes denoting the plural.

In Uyghur, the suffix -lar/ler is used after nouns to express the plural. In STDPTH, men (们) is one of the few suffixes that corresponds to the Uyghur suffix -lar/ler. Unlike -lar/ler in Uyghur, which can be used after any nouns or pronouns, men (们) in STDPTH is used only after nouns denoting an indefinite number of people. In XJSPTH, men (们) is found to be inserted after question words as well as nouns referring to objects or non-human creatures. Examples (2) and (3) below exemplify this phenomenon:

$\begin{array}{ll}\text { a. XJSPTH: } & \begin{array}{l}\text { Shei-men lai-le? } \\ \text { 谁们 来了? }\end{array} \\ \text { who-PL come-PAS } & \begin{array}{l}\text { b. STDPTH: } \\ \text { Shei lai-le? }\end{array} \\ & \text { 谁 来了? } \\ & \text { who come-PAST } \\ & \text { 'Who has arrived?' }\end{array}$

\begin{tabular}{|c|c|c|c|}
\hline \multirow[t]{3}{*}{ a. XJSPTH: } & Nimen & jexe & sengko-men. \\
\hline & 你们 & 这些 & 牲口 们。 \\
\hline & $2 \mathrm{PL}$ & these & animal-PL \\
\hline \multirow[t]{3}{*}{ b. STDPTH: } & $\begin{array}{l}\text { Nimen } \\
\text { 你们 }\end{array}$ & $\begin{array}{l}\text { zhexie } \\
\text { 这些 }\end{array}$ & $\begin{array}{l}\text { shengkou. } \\
\text { 牲口。 }\end{array}$ \\
\hline & $2 \mathrm{PL}$ & these & animal \\
\hline & 'You & als!' & \\
\hline
\end{tabular}

Another example of this kind is the extended use of the STDPTH phrase xiege (些个), which is closer to the Uyghur suffix -lar/ler as discussed above. In STDPTH, xiege (些个) is often used with demonstrative pronouns to denote an indefinite number of people or things. Uyghur speakers, however, tend to extend the use of xiege (些个) by using this phrase directly after a noun without the inclusion of any demonstrative pronouns. Examples (4) and (5) illustrate this kind of influence: 
(4) a. XJSPTH: Wang Li-xege hai mei lai.

王丽 些个 还没来。

Wang Li-PL yet NEG come

b. STDPTH: Wang Li tamen hai mei lai.

王丽他们还没来。

Wang L 3PL yet NEG come

'Wang Li and the others have not come yet.'

(5) a. XJSPTH: Yang- xiege haimei mai.

羊些个还没买。

Sheep- PL yet NEG buy

b. STDPTH: Yang haimei mai.

羊还没买。

Sheep yet NEG buy

'Sheep have not been bought yet.'

The imposition of men (们) and xiege (些个) from the existing suffixes to a previously non-existing aspect of the morphological pattern of STDPTH is another example of imposition by the speakers of Uyghur. This process of imposition is similar to what Heine and Kuteva (2005: 124-125) describe as "gap filling" in the existing system of a language. According to Heine and Kuteva, gap filling is common in cases where there is a lingua franca. Examples (4) and (5) illustrate this point.

4.3.2. Changing word order from SVO to SOV. A second aspect of the grammatical influence of Uyghur on STDPTH is found in the change of word order. Uyghur is a Turkic language (Austin 2008: 45). Typical word order in Uyghur is SOV and the word order is strictly fixed. In comparison, STDPTH is a language of the Sino-Tibetan family (Thurgood and LaPolla 2003: 3). Basic word order of the complex sentence in STDPTH is typically SVO (Li and Thompson 1989: 23; Sun 1996: 10) but word order is flexible enough for simple sentences in clear contexts to allow variations including SOV order, to occur. Gao (2008: 622) maintains that this is mainly due to the historically frequent contact of the Chinese language with languages of SOV word order such as Mongolian, Korean, Japanese and possibly Uyghur too. In brief, SOV can be said to be the best known word order in Uyghur while SVO is the most frequent word order in STDPTH.

Hinterholzl (2009: 45) maintains that word order changes are due to language contact. Speakers of Uyghur (SL) have been observed substituting the word order of their own language for the word order of STDPTH (RL) when they interact with Han people. Examples (6), (7), (8) and (9) exemplify the intense language contact between Uyghur and Putonghua in Xinjiang. 
(6)
a. XJSPTH:
$\begin{array}{llll}\text { Wo-de } & \text { xoji } & \text { maobing } & \text { qulai-le. } \\ \text { 我的 } & \text { 手机 } & \text { 毛病 } & \text { 出来了。 }\end{array}$
1SG-DET handset problem appear-PAST
b. STDPTH: Wo-de shouji chu maobing-le.
我的手机出毛病了。
1SG-DET handset come problem-PAST
'My mobile phone is not working.'

(7) a. XJSPTH: Ni pan qi-le-ma?

你饭 吃了吗?

2SG meal eat-PAST-Q

b. STDPTH: Ni chi fan-le-ma?

你吃 饭了吗?

2SG eat food-PAST-Q

'Have you eaten?'

(8)

$\begin{array}{lllll}\text { a. XJSPTH: } & \text { Wo zotan } & \text { danxi } & \text { kan-le. } \\ & \text { 我 昨天 } & \text { 电视 看了。 } \\ & \text { 1SG yesterday } \text { TV watch-PAST } \\ \text { b. STDPTH: } & \text { Wo zuotian } & \text { kan dianshi-le. } \\ & \text { 我 昨天 } & \text { 看 } & \text { 电视了。 } \\ & \text { 1SG yesterday watch TV-PAST } \\ & \text { 'I watched television yesterday.' }\end{array}$

(9) a. XJSPTH: Wo baza qu-le.

我巴扎去了。

1SG bazaar go-PAST

b. STDPTH: Wo qu bazha-le.

我去巴扎了。

1SG go bazaar-PAST

'I went to the bazaar.'

These examples show that SOV word order is quite common in XJSPTH. This is mainly due to the grammatical influence of Uyghur on STDPTH. On the other hand, the existence of SOV in XJSPTH clearly suggests the openness of STDPTH grammar to allowing SOV elements to enter its grammar.

4.3.3. Changing word order in negation. A third aspect of the grammatical influence of Uyghur on STDPTH is observed in the change of word order in negation. Negation in Uyghur is formed by using the post-verbal negator yoq or other negative suffixes. Unlike Uyghur, the negating word in STDPTH is often placed before the verb. STDPTH has apparently undergone some changes to bring it more in line with Uyghur by placing the negating word after the verb. This is exemplified by (10) and (11): 
(10)
a. XJSPTH: Pangzi ren meyo.
房子人没有。
house people NEG

b. STDPTH: Fangzi meiyou ren.

房子 没有人。

house NEG people

'No one is at home.'
a. XJSPTH: Jege xiqing wenti meyo.
这个事情问题没有。
this thing problem NEG
b. STDPTH: Zhege shiqing meiyou wenti.
这个 事情 没有 问题。
this thing NEG problem
'There is no problem with it.'

Evidence of the change of word order in STDPTH negation of is also found in the negation of the preposition he (和) 'with'. In STDPTH, the negative word $b u$ (不) 'no' is normally placed before the preposition he (和) 'with'. But in XJSPTH, the position of the negative word often appears toward the end of the sentence. This resembles the same pattern in Uyghur.

$\begin{array}{lllll}\text { a. XJSPTH: } & \text { Wo he ni bu } & \text { wan. } \\ & \text { 我和 你 不 } & \text { 玩。 } \\ & \text { 1PL with 2SG NEG } & \text { play } \\ \text { b. STDPTH: } & \text { Wo bu he ni wan. } & \text { 年 不 和 你 } & \text { 玩。 } \\ & \text { 1PL NEG with 2SG play } \\ & \text { 'I won't play with you.' }\end{array}$

These changes in the negation system of STDPTH suggest the influence of Uyghur as an explanation. As stated above, negation in Uyghur is formed by adding the negative suffix after the verb, which often appears at the end of a sentence.

4.3.4. Changing the word order of adverbials. In a situation where a probability or an ability of a person is to be expressed, the word order of Uyghur is Adverbial + Verb + -'ability', whereas in STDPTH, the word order is neng (能) 'can' + Adverbial + Verb. Evidence of Uyghur influence on the word order of adverbials in XJSPTH is found in the example below:
a. XJSPTH:
$\begin{array}{llll}\text { Wo } & \text { zai jeda } & \text { neng } & \text { zoxa-ma? } \\ \text { 我 } & \text { 在 这打 } & \text { 能 } & \text { 坐下吗? } \\ \text { 1SG in here } & \text { can } & \text { sit down-Q }\end{array}$ 
b. STDPTH: Wo neng zaizher zuoxia-ma?

我能在这儿坐下吗?

$1 \mathrm{SG}$ can in here sit down-Q

'Can I stay here?'

In a sentence in which an adverbial of place and an adverbial of duration occur together, both of the adverbials come before the verb in Uyghur. In STDPTH, however, although the adverbial of place is always placed before the verb, the adverbial of duration is normally treated as a complement of the verb. This can be exemplified in the examples below:

a. XJSPTH: Women zai Beijing santan

kaihui-le.

我们 在 北京 三天 开会咧。

$1 \mathrm{PL}$ in Beijing three days attend meeting-PAST.

b. STDPTH: Women zai Beijing kai-le san tian hui.

我们 在 北京 开了 三天会。

$1 \mathrm{PL}$ in Beijing attend-PAST three days meeting.

'We attended a three-day meeting in Beijing.'

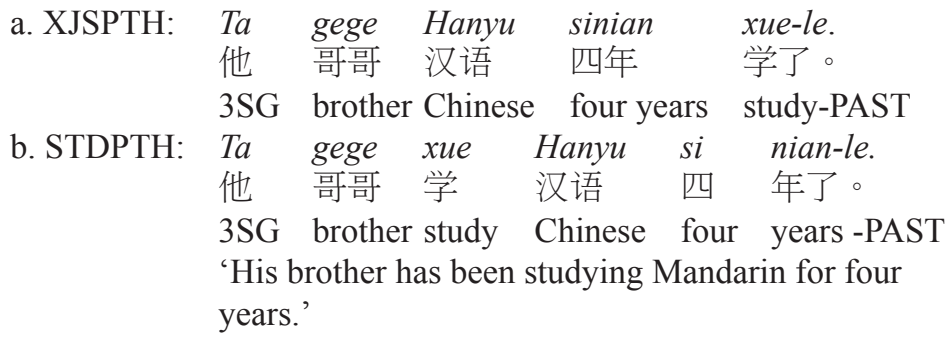

4.3.5. Omissions. Some omissions have been observed XJSPTH. These are the omission of the copular verb and the omission of prepositions. The copular verb and prepositions are important in STDPTH as they help to construct grammatically correct sentences. The omission of these two types of word can be taken as the direct influence of Uyghur.

Omitting the copular verb. The use of the copular verb shi (是) 'to be' is compulsory in many STDPTH sentences while the corresponding copular verb is optional in many Uyghur sentences. Uyghur speakers tend to omit shi when they communicate with a Chinese speaker. Examples (16) and (17) illustrate this aspect:

$\begin{array}{lllll}\text { a. XJSPTH: } & \text { Jege wenti minzu tanje wenti. } \\ & \text { 这个 问题 民族 团结 问题。 } \\ \text { this issue ethnic unity issue. }\end{array}$


b. STDPTH: Zhege wenti shi minzu tuanjie wenti.

这个问题 是 民族 团结问题。

this issue is ethnic unity issue

'This is an issue of ethnic unity.'
a. XJSPTH: Wo loxi, ni xueseng.
我 老师, 你 学生。
1SG teacher, 2SN student
b. STDPTH: Wo shi laoshi, ni shi xuesheng.
我是 老师, 你 是 学生。
1SG am teacher, 2SG are student
'I am a teacher and you are a student.'

Omitting prepositions. Another type of word that is likely to be omitted by Uyghur speakers is the preposition. In STDPTH there are many prepositions, while in Uyghur they appear as post-positions in the form of suffixes used after words to denote various grammatical functions. Uyghur speakers tend to omit the preposition in STDPTH by following the Uyghur model. Examples (18) and (19) exemplify this type of omission:

$\begin{array}{llll}\text { a. XJSPTH: } & \text { Nage dongxi na yixa. } & \\ & \text { 那 东西 拿 一下。 } \\ & \text { That object hold once } \\ \text { b. STDPTH: } & \text { Ba neige dongxi na yixia. } \\ & \text { 把 那 东西 拿 一下。 } \\ & \text { PREP that object hold once } \\ & \text { 'Please hold it.' } & \\ \text { a. XJSPTH: } & \text { Mobi } \text { xe-de } \text { jege zi. } \\ & \text { 毛笔 写的 这个 字。 } \\ & \text { brush-pen write-DET this word } \\ \text { b. STDPTH: } & \text { Yong mabi } \text { xie-de } & \text { zhege zi. } \\ & \text { 用 毛笔 写的 } \text { 这个 字。 } \\ & \text { with brush-pen write-DET this word. } \\ & \text { 'This word is written with a brush-pen.' }\end{array}$

\subsection{Semantic elements}

According to Turell (2001: 368), semantic influence is defined as the literal translation, from one language into another, of idiomatic expressions such as similes and metaphors represented by a language unit, with no external indication showing their linguistic root. Examples (20), (21), (22), (23) and (24) exemplify this phenomenon of language contact: 


$$
\begin{array}{ll}
\text { XJSPTH: } & N i \text { xi ge kabake naodai. } \\
& \text { 你 是 个 卡巴克 脑袋。 } \\
& \text { 'You are a stupid man.' }
\end{array}
$$

The literal translation of (20) is: 'You are a pumpkin head'. This expression is unique to the Uyghur culture. In Xinjiang, Uyghur farmers cultivate a kind of pumpkin which can grow very big. After they have been processed, Uyghur farmers often use them as containers. In Uyghur, the intended meaning of 'a pumpkin head' is a person who is stupid and stubborn.

$$
\begin{array}{ll}
\text { XJSPTH: } & N i \text { jintan qu nage dipang qi japan le? } \\
& \text { 你 今天 去 哪个 地方 吃 抓饭 了? } \\
\text { 'Where did you go for a wedding?' }
\end{array}
$$

The literal translation of (21) is 'Where did you go and eat pilaf today?' In Uyghur culture, serving pilaf is a must at a Uyghur wedding. The intended meaning of the question is not where the person had pilaf but rather where this person went to attend a wedding.

$$
\begin{array}{lll}
\text { XJSPTH: } & N i \text { duzi buyo jang. } \\
& \text { 你 肚子 不 要涨。 }
\end{array}
$$

The literal meaning of (22) is 'Do not let your belly swell'. In Uyghur, if someone's belly is said to be swollen, that person is angry.

$$
\begin{array}{ll}
\text { XJSPTH: Ta nage ren yanjing xo. } \\
\\
\text { 他 那个 人 眼睛 小。 }
\end{array}
$$

The literal translation of (23) is that 'That man has got a pair of small eyes'. In Uyghur, if someone is said to have a small pair of eyes, that person is stingy.

\section{Conclusion}

Uyghur and Putonghua are languages that are genetically unrelated. However, the results of the present study show strong evidence of the influence of Uyghur on STDPTH under the intense language contact situation in Xinjiang. The influence is largely from Uyghur, with the imposition of Uyghur elements onto the spoken language. The agents of this act of imposition are Uyghurs who speak imperfect Putonghua as a second language. These agents transfer elements of their dominant language to Putonghua and cause changes in the language. As a result of this, changes have now taken place in phonology, lexis, grammar and semantics of STDPTH in Xinjiang. Phonologically, 
changes have taken place at the suprasegmental level through the dropping of tones, the changing of stressed syllables, the extension of the vowel length and the substitution of certain vowels and consonants. Lexically, nouns - mainly those relating to the unique Uyghur culture - have been introduced into STDPTH in Xinjiang. Changes have been made to these Uyghur words to make them sound more like STDPTH. Grammatically, the influence of Uyghur on STDPTH is found mainly in the aspect of word order. Changes of word order include changing the SVO pattern to that of SOV, changing word order in negation and in the positioning of adverbials. Omission of the copular verb and certain prepositions has also been observed. These grammatical changes are all imposed onto STDPTH on the basis of the Uyghur model. Semantically, some interesting Uyghur expressions have been translated literally into STDPTH and have been found in use locally in various situations.

Uyghur elements found in STDPTH raises an important linguistic question: should these elements be categorized as an interlanguage or a new variety of XJPTH? An interlanguage is spoken by individuals and it is temporary due to its feature as a changing language system. According to this understanding, these Uyghur elements in STDPTH do not qualify as an interlanguage. A new variety of a language is spoken by the community and it is systematic and not temporary. Relating this understanding to the results of the data, it can be proposed that the Uyghur elements found in XJPTH are in fact a new variety of XJPTH.

Some implications can be drawn from the results of the data. Changes in the phonological, lexical, grammatical and semantic structures of STDPTH imply the amenability of STDPTH to changes brought about externally. The most obvious evidence of this is the change of the syntactic structure from the frequent pattern of SVO to SOV.

Another implication is the future of XJSPTH in Xinjiang. Two different scenarios can be imagined: (1) XJSPTH will spread, and (2) XJSPTH will recede and disappear. Scenario 1 is based on the economic development in Xinjiang. In recent years, the pace of urbanization in Xinjiang has accelerated. As a result of this, many monolingual Uyghurs, particularly those in the south and from rural Xinjiang, have had more opportunities for exposure to XJSPTH. This might help to spread XJSPTH among these Uyghurs. XJSPTH might also spread to other parts of China, as the economic development in Xinjiang and in other provinces of the country is expected to draw more Chinese migrants in both directions. Scenario 2 is based on the current implementation of bilingual education program for Uyghur students in Xinjiang. Putonghua is now being introduced at the pre-school level. Schools separated by ethnicity are now being merged with the Chinese schools. These may certainly create more favorable conditions for the Uyghurs to learn Putonghua. As a result of this, more and more Uyghurs are likely to attain a higher proficiency level in Putonghua, 
which might lead to the recession and disappearance of XJSPTH as a variety of Putonghua in Xinjiang.

University of Manchester

Correspondence address: Ablimit.Baki@manchester.ac.uk

\section{References}

Appel, Rene \& Pieter Muysken. 2006. Language contact and bilingualism. Amsterdam: Amsterdam University Press.

Austin, Peter (ed.). 2008. One thousand languages: living, endangered, and lost. Berkley: University of California Press.

Brisk, Maria. 2006. Bilingual education: from compensatory to quality schooling. London: Routledge.

Byram, Michael. 2004. Routledge encyclopedia of language teaching and learning. London: Routledge.

Chen, Ping. 1999. Modern Chinese: history and sociolinguistics. Cambridge: Cambridge University Press.

Chinese Census. 2003. 2000 nian renkou pucha Zhongguo minzu renkou ziliao [2000 census of ethnic groups in China]. Beijing: Nationality Press.

Coelho, Elizabeth. 1998. Teaching and learning in multicultural schools: an integrated approach. UK: Multilingual Matters.

van Coetsem, Frans. 1988. Loan phonology and two transfer types in language contact. Berlin: Walter de Gruyter.

van Coetsem, Frans. 2000. A general and unified theory of the transmission process in language contact. Heidelberg: Winter.

Davies, Alan. 1989. Is international English an interlanguage? TESOL Quarterly. 23(3). 447467.

Dulay, Heidi, Marina Burt \& Stephen Krashen. 1982. Language 2. Oxford: Oxford University Press.

Dwyer, Arienne. 2005. The Xinjiang conflict: Uyghur identity, language policy and political discourse. Policy Studies 15. East-West Center Washington.

Gao, Mobo C. F. 2000. Mandarin Chinese: an introduction. Oxford: Oxford University Press.

Gao, Qian. 2008. Word order in Mandarin: reading and speaking. In Marjorie K. M. Chan \& Hana Kang (eds.), Proceedings of the 20th North American Conference on Chinese Linguistics (NACCL-20), 2, 611-626. Columbus, Ohio: Ohio State University Press.

Heine, Bernd \& Tania Kuteva. 2005. Language contact and grammatical change. Cambridge: Cambridge University Press.

Hess, Steve. 2009. Dividing and conquering the shop floor: Uyghur labor export and labor segmentation in China's industrial east. Central Asia Survey 28(4). 403-416.

Hinterholzl, Roland. 2009. The role of information structure in word order variation and word order change. In Roland Hinterholzl \& Svetlana Petrova (eds.), Information structure and language change: new approaches to word order. Berlin \& New York: Walter de Gruyter.

Huang, Borong \& Xudong Liao. 1983. Xiandai Hanyu [Modern Chinese]. Lanzhou: Gansu People's Publishing House. 
Johanson, Lars. 2002. Contact-induced change in a code-copying framework. In Mari C. Jones \& Edith Esch (eds.), Language change: the interplay of internal, external and extra-linguistic factors, 285-313. Berlin \& New York: Mouton de Gruyter.

Kaltman, Blaine. 2007. Under the heel of the dragon: Islam, racism, crime, and the Uyghur in China. Columbus, Ohio: Ohio University Press.

Kang, Jian. 2003. Xinjiang yao fazhan, Hanyu jiaoyu yao xian xing [If Xinjiang is to be developed, Chinese language education must go first]. Yuyan Yu Fanyi [Language and Translation] 2. 63-66.

Li, Charles N. \& Sandra A. Thompson. 1989. Modern Chinese: a functional reference grammar. Berkley: University of California Press.

Li, Wei. 2010. Contact. In Jan-Ola Ostman, Jef Verschueren \& Jurgen Jaspers (eds.), Society and language use, 127-139. Amsterdam: John Benjamin.

Li, Xia. 2005. Qitaihua yu Putonghua de sheng, yun and diao de bijiao [A comparison of tones, vowels and pitches between Qitai speech and Putonghua] Wuluтиqi Shi Jiaоуи Хиеуиап Хиеbao [Journal of Adult Education Institute of Urumqi City] 2(13). (Page numbers not available).

Liu, Huei Mei, Feng Tsao-Ming \& Patricia Khul. 2007. Acoustic analysis of lexical tone in Mandarin infant-directed speech. Development Psychology 43(4). 912-917.

Ma, Kezhang. 2007. Xinjiang hanyu fangyan Lan-Yin guanhua Beijiang pian de daibiao hua zhouyi [On the representative variant of Lan-Yin Mandarin Cluster in north Xinjiang as a variety of Xinjiang Putonghua] Wulumuqi Shi Jiaoyu Xueyuan Xuebao [Journal of Adult Education Institute of Urumqi City] 1(15). 42-47.

Ma, Rong. 2003. Economic development, labour transference, and minority education in the West China. Development and Society 32(2). 125-145.

Manley, Marilyn S. 2007. Cross-linguistic influence of the Cuzco Quechua epistemic system on Andean Spanish. In Kim Potowski \& Richard Cameron (eds), Spanish in contact: policy, social and linguistic inquiries. Amsterdam: John Benjamin Publishing Group.

Mirsultan. 1987. Hazirqi zaman Uyghur tili [Modern Uyghur language]. Urumqi: Peoples Publishing Home of Xinjiang.

Moneyhon, Matthew D. 2004. Taming China's "Wild West": ethnic conflict in Xinjiang. Peace, Conflict, and Development: An Interdisciplinary Journal 5(5). 2-23.

Moody, Theodore William, Francis X. Martin \& Francis John Byrne. 1991. A new history of Ireland: Volume III: Early modern Ireland 1534-1691. Oxford: Oxford University Press.

Niu, Ruji. 2000. Xiyu yuyan jiechu gaishuo [A general introduction to language contact in the Western Region]. Journal of the Central University for Nationalities 4(27). 122-125.

Niyaz, Haliq. 1997. Uyghur tilidin asas [The Basic Uyghur]. Urumqi: Xinjiang University Press.

Norman, Jerry. 1988. Chinese. Cambridge: Cambridge University Press.

Odlin, Terence. 1989. Language transfer: cross-linguistic influence in language learning. Cambridge: Cambridge University Press.

Selinker, Larry. 1872. Interlanguage. International review of applied linguistics in language teaching 10. 209-232.

Silva-Corvalán, Carmen (ed.). 1995. Spanish in four continents, studies in language contact and bilingualism. Washington D.C.: Georgetown University Press.

Snow, Donald B. 2004. Cantonese as a written language: the growth of a written Chinese vernacular. Hong Kong: Hong Kong University Press.

Starr, S. Frederick. 2004. Xinjiang: China's Muslim borderland. London: M. E. Sharpe.

Sun, Chaofen. 1996. Word-order change and grammaticalization in the history of Chinese. Stanford: Stanford University Press.

Swain, Merrill \& Sharon Lapkin. 1991. Additive bilingualism and French immersion education: the roles of language proficiency and literacy. In Allan G. Reynolds \& Wallace E. Lambert 


\section{A. Baki}

(eds.), Bilingualism, multilingualism, and second language learning, 203-216. London: Routledge.

Thomason, Sarah Grey \& Terrence Kaufman. 1988. Language contact, creolization, and genetic linguistics. Berkley: University of California Press.

Thomason, Sarah Grey. 2001. Language contact. Edinburgh University Press.

Thurgood, Graham \& Randy J. LaPolla. 2003. The Sino-Tibetan languages. London: Routledge. Turell, M. Teresa. 2001. Multilingualism in Spain. UK: Multilingual Matters.

Vermeer, Anne. 1985. Moroccan and Turkish children in the Netherlands: the influence of social factors on tempo and structure of L2 acquisition. In Guus Extra (ed.), Ethnic minorities and Dutch as a second language, 49-63. Berlin: Walter de Gruyter.

Ye, Feisheng \& Tongqiang Xu. 1997. Yuyan xue gangyao [An outline of linguistics]. Beijing: Peking University Press.

Zhou, Lei. 2007. Xinjiang Weiwu'er Zizhiqu de Zhongyuan Guanhua [On Zhongyuan Mandarin in Xinjiang Uyghur Autonomous Region] Fangyan [Dialect] 2. 163-166.

Zhou, Minglang. 2006. Theorizing language contact, spread and variation in status planning: a case study of modern standard Chinese. Journal of Asian Pacific Communication 16(2). 159174. 